\title{
What do we need to know about e-learning standards?
}

\author{
M. Llamas, L. Anido, J. Rodríguez, M. Fernández, J. Santos and M. Caeiro \\ Campus UniversitarioVigo, Spain
}

\begin{abstract}
The e-learning domain is involved in a deep standardization process. Several topics related to e-learning authoring, delivering, and management are being discussed to obtain general accepted recommendations. This paper provides a clear picture about e-learning standardization. It presents the main contributors, the discussed topics, and what the different stakeholders involved in e-learning systems need to know about them.
\end{abstract}

Key words: E-learning systems, Standardization

\section{INTRODUCTION}

The application of information and communication technologies to the learning domain has been very fruitful. Many e-learning systems and resources have been developed, and as usual, problems of reusability and interoperability appear.

As a consequence, a standardization process was initiated. Currently, this effort has produced some proposals for e-learning standards. Although most of them are in draft form, and therefore exhibit varying degrees of stability, eventually, some of them will become generally accepted standards of which people involved in the e-learning business should be aware.

This paper presents this standardization process. The first part (section 2) introduces the current fields and proposals. Section 3 shows what the different stakeholders that participate in e-learning business should know about them. The last section summarizes this survey work.

The original version of this chapter was revised: The copyright line was incorrect. This has been corrected. The Erratum to this chapter is available at DOI: 10.1007/978-0-387-35700-3_33 


\section{E-LEARNING STANDARDIZATION}

The e-learning standardization process was initiated by several unrelated groups and projects in order to arrange formats for data interchange. Nowadays, the standardization is mainly driven by a few bodies (c.f. Table 1). They are organizations devoted to produce international standards (e.g. IEEE or ISO/IEC), great consumers of educational software (e.g. AICC, US DoD), and some governmental initiatives (e.g. IMS, CEN/ISSS/LT).

Table 1. Main learning standardization bodies

\begin{tabular}{|l|l|l|}
\hline Acronym & Initiative & URL \\
\hline DoD ADL & $\begin{array}{l}\text { US Department of Defense Advanced } \\
\text { Distributed Learning }\end{array}$ & http://www.adlnet.org \\
\hline AICC & Aviation Industry CBT Committee & http://www.aicc.org \\
\hline CEN/ISSS/LT & $\begin{array}{l}\text { European Committee for Standardization / } \\
\text { Information Society Standardization System } \\
\text { / Learning Technologies Workshop }\end{array}$ & $\begin{array}{l}\text { http://www.cenorm.be/isss/ } \\
\text { Workshop/lt }\end{array}$ \\
\hline IEEE LTSC & $\begin{array}{l}\text { IEEE Learning Technologies } \\
\text { Standardization Committee }\end{array}$ & http://ltsc.ieee.org \\
\hline IMS & IMS Project \&Consortium & http://www.imsproject.org \\
\hline $\begin{array}{l}\text { ISO/IEC } \\
\text { JTC12 SC36 }\end{array}$ & $\begin{array}{l}\text { ISO/IEC Joint Committee for the } \\
\text { Standardization of Learning Technologies }\end{array}$ & http://www.jtclsc36.org \\
\hline
\end{tabular}

The work of these groups has been focused on specific topics. In Santos et al (2002) we presented the results of a recent survey about the key standardization fields and proposals. The main topics of standardization identified in that paper are:
a) Educational metadata.
b) Content structures.
c) Aggregation models.
d) Question and test interoperability.
e) Learners information.
f) Runtime environments.
g) Frameworks and architectures.
h) Brokerage and digital repositories.

Other minor topics subject to this standardization process are: intellectual property and digital rights, accessibility, multilingual and cultural diversity, internationalization and localization, user interfaces, media formats, or hardware systems.

There is a new and very important standardization field: Educational Modelling Languages (EMLs). The main goal of EMLs is not to support just one, but as many pedagogies as possible. Previous standardization topics 
(e.g. content structures, runtime environments) preestablish a particular pedagogical approach. They allow only for some simple ordering and sequencing of resources to be experienced by learners. In order to support different pedagogical approaches, an EML document has to describe: people that participate, types of roles to play (e.g. teacher and learner), activities to perform and specific order, environment that contains objects (e.g. text, audio or pictures) and provides services (e.g. chat, conference).

There are several proposals for EMLs managing different concepts. The CEN/ISSS Workshop on Learning Technologies produced a survey on EMLs, Rawlings et al (2002). According to it 'an EML is a semantic rich information model and binding, describing the content and process within "units of learning" from a pedagogical perspective'.

The IMS Learning Design in Koper et al (2002) is the most outstanding proposal in the field of EMLs. It provides a generic and flexible language that supports the definition of learning designs independently of pedagogical approaches. It is an integrative proposal of a number of other existing IMS specifications: IMS content packaging, IMS metadata, IMS question and test interoperability, IMS competency definitions, and others.

IMS Learning Design is completely new as an IMS specification. Though it has been accepted as a public draft very recently, October 2002, the principles behind it have been around for a few years in the form of the Open University of the Netherlands' (OUNL) Educational Modelling Language (EML), Koper (2002).

\section{STAKEHOLDERS INVOLVED}

This section describes what the different actors involved in e-learning business should know about the e-learning standardization process. We classify these actors as stakeholders according to their responsibilities.

\subsection{Developers of learning systems}

These are the software engineers and designers responsible for the development of learning management systems. They have to know about all the standards, because they have to build the software that manages the data formats described in the different specifications.

There are some proposals for Frameworks and Architectures that are specially important for these actors. They define services and interfaces in order to improve the development of components and support the interoperation among systems. There are concrete proposals for runtime environments. These specifications define how a learning object should be 
launched, and how learning objects and learning management systems should interact.

The new specifications in learning design and EMLs are very interesting because they provide a language to support the specification of learning designs according to different learning approaches. Therefore, a system that executes EMLs could support any learning approach, at least in theory.

\subsection{Technical staff}

They are responsible for maintaining learning systems and managing them at runtime. Metadata instances usually include information on installation requirements. There are also standards to define which multimedia formats should be used, minimum requirements for software and hardware to guarantee an adequate learning environment on the student's side and packaging specifications to define how learning objects and content aggregations are transferred from content developers to learning providers.

\subsection{Administrative staff}

The administrative staff are responsible for maintaining the users and resources that participate in a given institution. Therefore, they should consider standardized formats for both learning resources and learner records.

On the one hand, they need to know how to search and transfer learning resources. So they have to be aware of Brokerage Platforms, Digital Repositories and Metadata recommendations.

On the other hand, they have to manage learners and their enrolment in courses. There are some proposals about how to maintain Learners Information, to support the management of learners. The use of a common data model to describe students' personal, academic performance and preference information would promote interoperability among heterogeneous institutions making it easier to transfer a student record from one institution to another.

\subsection{Developers of learning objects}

The developers of learning objects are the authors and multimedia specialists responsible for developing learning objects. Learning objects are used to compose courses and to arrange the learning activities. They should know the specifications that prescribe the format of such objects, namely:

- Content Structures, defining static structure and dynamic behaviour of courses, according to student interaction. 
- Question and test interoperability specifications, prescribing formats for questionnaires and tests, both for rendering and evaluation.

Development of learning objects will require a concrete knowledge of the features required. In this way, some proposals as described in Hyde (2001) have identified the need to provide learner records to the developers of learning objects. Learner records maintain the results of the interaction of the learners with learning objects. This information may be used to assess the quality of the developed learning objects and decide whether they should be modified or not.

In addition to the development of learning objects these actors have to manage them. For this purpose learning metadata is needed. Metadata is used to provide information on learning objects, and it is very useful for classifying, organizing and searching purposes.

Other recommendations should also be taken into account. For example, accessibility requirements have received the attention of both e-learning standardization and World Wide Web communities.

\subsection{Vendors of learning objects}

Those responsible for commercial development of learning objects should be able to publicize them in adequate forums and through appropriate mechanisms in order to offer them to possible customers.

Brokerage Platforms provide environments where vendors and customers can get in contact. They leverage the functionalities of a typical search engine supporting new customer services, content delivery and even accounting and billing. In order to publicize their products, these vendors need to know about Metatada, to be able to populate the brokerage systems' catalogues.

They should also be aware of Digital Repositories specifications. There are some specifications that provide a reference architecture for the storage of learning resources, defining services and interfaces. Learning object vendors should use such repositories to maintain their resource catalogues.

In order to transfer learning resources or complete courses they need to be aware of specifications for Aggregation Models. Typically, a learning resource or course is composed of several elements. These specifications define the way to aggregate them into appropriate packages to be transferred between institutions.

\subsection{Teachers}

Teachers are often responsible for deciding which courses and pedagogical material are used in their educational institutions. They are the 
actors responsible for designing and planning the learning experiences that should be experienced by the learners. In this direction, EML specifications are very interesting, because they provide flexibility for the specification of learning designs. Content Structures may also be useful, because sometimes they may wish to create a new course from certain learning resources.

In any case, teachers are responsible for arranging learning objects in order to provide learning. So they have to evaluate learning objects, and this is quite difficult without previous hands-on experience. The educational category in most metadata schemes tries to overcome this situation providing as much information as possible on the pedagogical uses of learning objects. Teachers must know how to interpret and use information provided by metadata, not only to decide which learning object is best, but also to help others to make future decisions. In fact, many metadata models include an annotation category that can be used by lecturers who have already used the learning objects. This category may reflect their comments and hints on future use.

\subsection{Tutors}

Tutors are responsible for monitoring the evolution of the learners and supervise their progress according to the planning established by teachers. They are the persons that monitor and control the learning process.

Tutors have to know about the structure of the learning design or the courses, but not to the same degree as teachers. Especially, they should be aware of the data maintained in the learner records, particularly data related to the interaction of learners with the learning objects.

In fact, all this information could be processed by the particular learning system and provided to the tutors in a transparent way, so they do not need to be aware of the standards managed.

\subsection{Students}

Students are the final users of educational tools and platforms. Although the use of standards should be transparent for them, students will benefit the most in a standardized e-learning scenario. The use of standards promotes learning object exchange and interoperability among different institutions, and therefore provides students with a higher quality learning environment. 


\section{CONCLUSIONS}

In this paper we have presented the most important standardization topics in the e-learning domain and their relation with the different stakeholders involved. Table 2 presents a summary of the elements considered in this paper.

Table 2. Stakeholders and related e-learning standardization fields

\begin{tabular}{|c|c|c|c|c|c|c|c|c|}
\hline $\begin{array}{l}\quad \text { Stakeholder } \\
\text { Field of } \\
\text { Standardization }\end{array}$ & 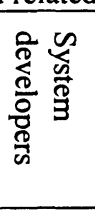 & 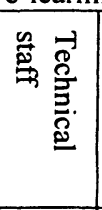 & 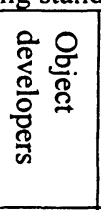 & 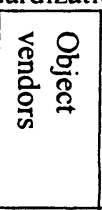 & 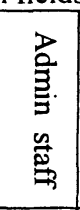 & 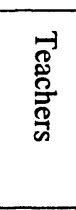 & $\vec{E}$ & $\begin{array}{l}5 \\
8 \\
8\end{array}$ \\
\hline $\begin{array}{l}\text { Educational } \\
\text { Metadata }\end{array}$ & $\mathrm{X}$ & $\mathrm{X}$ & $\mathrm{x}$ & $\mathrm{X}$ & $\mathrm{X}$ & $\mathrm{X}$ & & \\
\hline Content structures & $\mathrm{X}$ & & $\mathrm{X}$ & & & $\mathrm{X}$ & $\mathrm{X}$ & \\
\hline $\begin{array}{l}\text { Aggregation } \\
\text { models }\end{array}$ & $\mathrm{X}$ & $\mathrm{X}$ & & $\mathrm{X}$ & $\mathrm{X}$ & & & \\
\hline $\begin{array}{l}\text { Question and test } \\
\text { interoperability }\end{array}$ & $\mathrm{x}$ & & $x$ & & & $\mathrm{X}$ & & \\
\hline $\begin{array}{l}\text { Learners } \\
\text { information }\end{array}$ & $\mathrm{X}$ & & $\mathrm{X}$ & & $\mathrm{x}$ & $\mathrm{X}$ & $\mathrm{X}$ & $\mathrm{X}$ \\
\hline $\begin{array}{l}\text { Runtime } \\
\text { environments }\end{array}$ & $\mathrm{X}$ & $\mathrm{X}$ & & & & & & \\
\hline $\begin{array}{l}\text { Frameworks and } \\
\text { architectures }\end{array}$ & $\mathrm{X}$ & $\mathrm{X}$ & & $\mathrm{X}$ & $\mathrm{X}$ & & & \\
\hline $\begin{array}{l}\text { Brokerage } \\
\text { architectures }\end{array}$ & $\mathrm{X}$ & & & $\mathrm{X}$ & $\mathrm{X}$ & & & \\
\hline Digital repositories & $\mathrm{X}$ & & & $\mathrm{X}$ & $\mathrm{X}$ & & & \\
\hline $\begin{array}{l}\text { Competency } \\
\text { definitions }\end{array}$ & $X$ & & $\mathrm{X}$ & $\mathrm{X}$ & $\mathrm{X}$ & $\mathrm{X}$ & & \\
\hline $\begin{array}{l}\text { Educational } \\
\text { Modelling } \\
\text { Languages }\end{array}$ & $\mathrm{X}$ & $\mathrm{X}$ & & & & $\mathrm{x}$ & $\mathrm{X}$ & \\
\hline
\end{tabular}

Those who must be aware of the different standards and proposals are those developing learning objects, learning management systems and the software tools needed to support other stakeholders' responsibilities. However, we have referenced the different roles involved in an e-learning environment to discuss those specifications affecting the software tools used by the corresponding stakeholders.

The number of draft specifications and working groups is considerable, but some final results have already being issued (e.g. LOM). We consider that the number of topics proposed for standardization will increase in the near future. Current specifications are mainly devoted to the definition of common data formats and models. These efforts support the basis for 
interoperability, but in order to complete the standardization of the elearning domain new specifications are required, describing the behaviour, interfaces and functionalities offered by learning systems.

Therefore, the e-learning standardization process is an active, continuous process that will last for years to come, until a clear, precise, and generally accepted set of standards for educational-related systems is developed. Eventually, e-learning standards will influence the next generation of virtual learning environments. The actors involved in this domain should be aware of such standards in order to cope with their responsibilities.

\section{ACKNOWLEDGMENTS}

We want to thank the Spanish Ministry of Science and Technology for their partial support to this work under grant CORBALearn: A Standardguided domain interface for e-learning (TIC2001-3767).

\section{REFERENCES}

Hyde, J. 'CMI Guidelines for Interoperability'. Version 3.5. Technical Report. Aviation Industry CBT Committee. April 2001.

Koper, R.: 'Modeling Units of Study from a Pedagogical Perspective: the Pedagogical Metamodel behind EML' Version 2. First Draft, Educational Technology Expertise Centre Open University of the Netherlands, 2001

Koper, R., Olivier, B. and Anderson, T. (Editors): 'IMS Learning Design Information Model' Version 1.0. Public Draft, IMS Global Learning Consortium, 2002

Rawlings, A., van Rosmalen, P., Koper, R., Rodrígez-Artacho M. and Lefrere, P.: 'Survey of Educational Modelling Languages (EMLs)'. Version 1. CEN/ISSS WS/LT Learning Technologies Workshop, 2002.

Santos, J., Caeiro, M., Rodríguez, J., and Anido, L. 'Standardization in TelE-learning. A critical análisis'. 17th IFIP World Computer Congress. TelE-LEARNING. The Challenge for the Third Millennium. pps. 321-328. Kluwer Academic Publishers. ISBN: 1-40207219-8. August 25-30, 2002. Montreal (Canada). 